\title{
What Determines the Electrochemical Properties of Nitrogenated Amorphous Carbon Thin Films?
}

\author{
Jarkko Etula, Niklas Wester, Touko Liljeström, Sami Sainio, Tommi Palomäki, Kai Arstila, \\ Timo Sajavaara, Jari Koskinen, Miguel A. Caro, and Tomi Laurila*
}

Cite This: Chem. Mater. 2021, 33, 6813-6824

Read Online

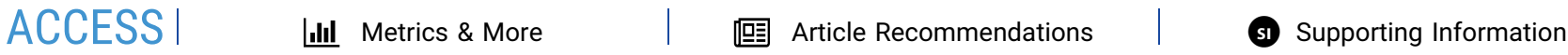

ABSTRACT: Linking structural and compositional features with the observed electrochemical performance is often ambiguous and sensitive to known and unknown impurities. Here an extensive experimental investigation augmented by computational analyses is linked to the electrochemical characterization of in situ nitrogen-doped tetrahedral amorphous carbon thin films (ta-C:N). Raman spectroscopy combined with $\mathrm{X}$-ray reflectivity shows nitrogen disrupting the $\mathrm{sp}^{3} \mathrm{C}-\mathrm{C}$ structure of the reference ta- $\mathrm{C}$, supported by the observations of graphitic nitrogen substitution in X-ray absorption spectroscopy. The surface roughness also increases, as observed in atomic force microscopy and atomic-level computational analyses. These changes are linked to significant increases in the hydrogen and oxygen content of the films by utilizing time-of-flight elastic recoil detection analysis.

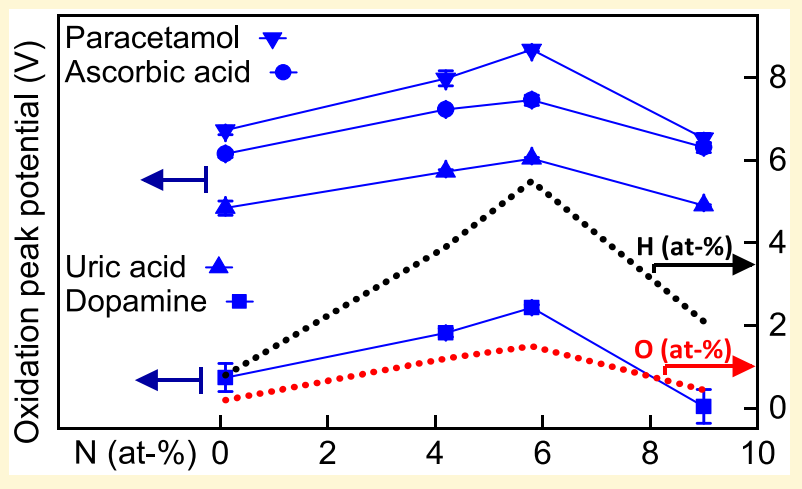
The conductivity of the films increases as a function of the nitrogen content, which is seen as a facile reversible outer-sphere redox reaction on ta-C: $\mathrm{N}$ electrodes. However, for the surface-sensitive inner-sphere redox (ISR) analytes, it is shown that the electrochemical response instead follows the oxygen and hydrogen content. We argue that the passivation of the required surface adsorption sites by hydrogen decreases the rates of all of the chemically different ISR probes investigated on nitrogenated surfaces significantly below that of the nitrogen-free reference sample. This hypothesis can be used to readily rationalize many of the contradictory electrochemical results reported in the literature.

\section{INTRODUCTION}

Amorphous carbon (a-C) and its high $\mathrm{sp}^{3}$-bonded, carboncontaining variant, the so-called tetrahedral amorphous carbon (ta-C), have recently received renewed attention as candidate electrode materials in various applications. ${ }^{1-6}$ They have been utilized in biomolecule detection to measure, for example, dopamine (DA), ${ }^{7}$ as corrosion protection layers, ${ }^{8}$ and as a robust platform to realize more complex carbonaceous sensing materials. ${ }^{9,10}$ Despite their many attractive properties, such as a wide potential window, low background current, readily functionalizable surfaces, and generally favorable interaction with various cell types, ${ }^{1}$ their sometimes inherently low conductivity and chemical reactivity, especially in the case of ta-C, have posed some challenges in their electrochemical applications. ${ }^{11}$ Thus alloying ta-C films with nitrogen to increase their conductivity ${ }^{12-14}$ and electrochemical performance ${ }^{4,15-20}$ has been widely attempted. Likewise, the addition of nitrogen to amorphous carbon films with a lower $\mathrm{sp}^{3}$ fraction and their resulting electrochemical performance have recently been addressed. ${ }^{21-23}$ Although some very detailed investigations about the electronic, structural, and chemical effects that $\mathrm{N}$ has on a-C have been reported, ${ }^{24-26}$ the electrochemical behavior of nitrogenated a-C films remains ambiguously understood to date. In particular, there is a drastically different behavior between outer-sphere redox (OSR) probes, which are practically insensitive to surface chemical properties but "react" to changes in the electronic properties of electrode material, and inner-sphere redox (ISR) probes, which are highly sensitive to surface chemistry. For example, Behan et al. ${ }^{23}$ observed that the reaction kinetics of the OSR probes increased as a function of increasing nitrogen content, whereas the opposite trend was noted for the ISR probes. Similar unexplained results can be widely found in the literature for a-C thin films. ${ }^{1}$

To understand this behavior, researchers have sketched various models that would explain these observations by invoking effects caused by differently bonded nitrogen or how the presence of nitrogen affects the local chemical environment of the a-C films. ${ }^{21-23}$ Density functional theory (DFT) studies

Received: $\quad$ May 2, 2021

Revised: July 23, 2021

Published: August 23, 2021 

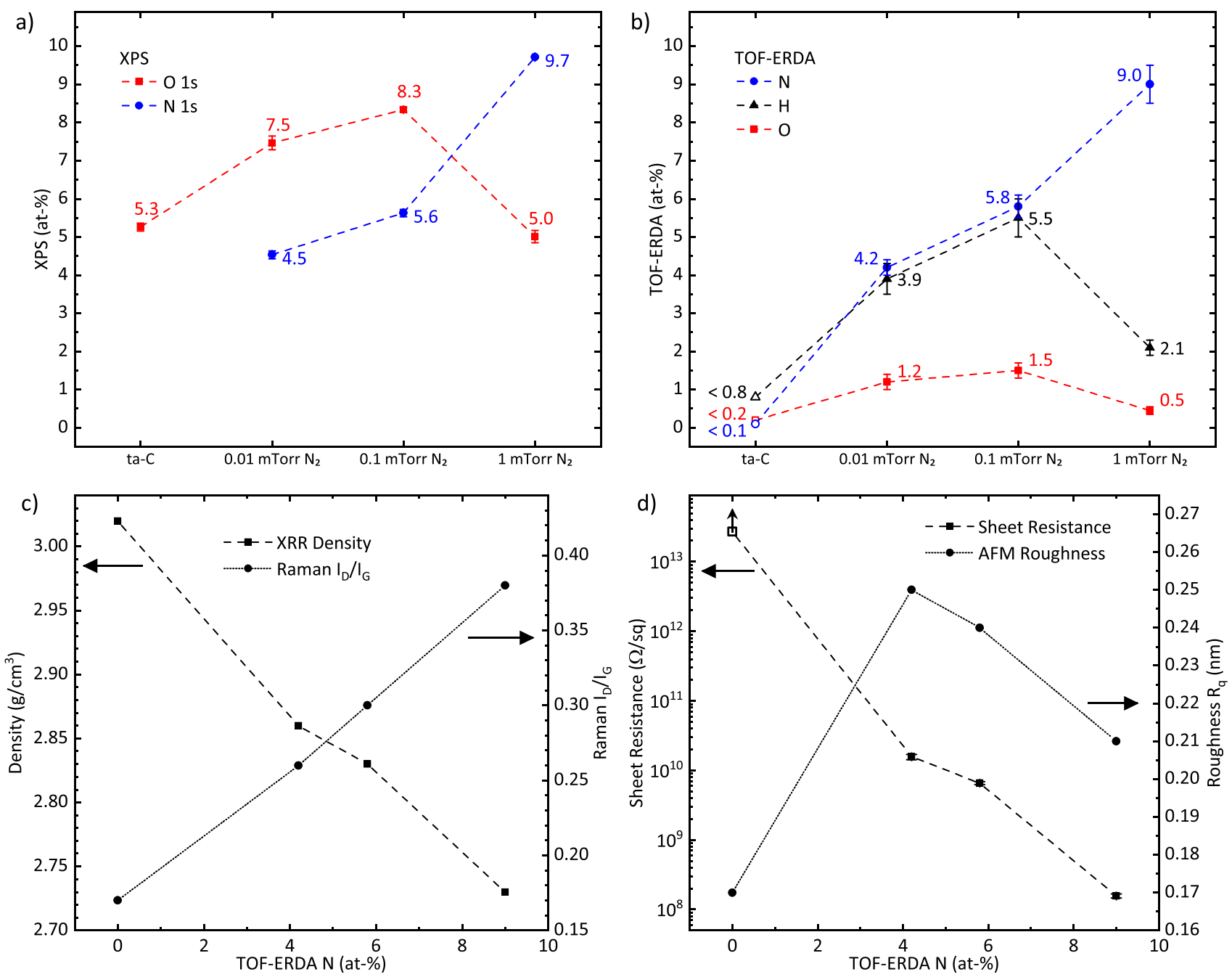

Figure 1. Summary of physical characteristics. (a) Surface elemental composition as measured by XPS (Figure S1 and Table S1 in the Supporting Information). (b) TOF-ERDA elemental compositions integrated from the depth regions shown in Figure 2. Open symbols refer to values outside experimental resolution. (c) XRR density and Raman carbon $I_{\mathrm{D}} / I_{\mathrm{G}}$ ratio plotted as a function of the TOF-ERDA nitrogen content. ${ }^{25}$ (d) Sheet resistance and AFM root-mean-square (RMS) roughness $\left(R_{\mathrm{q}}\right)$ plotted as a function of TOF-ERDA N (at \%). See Figures S2-S4 in the Supporting Information for XRR, Raman, and AFM results.

have also been used to address these issues ${ }^{22}$ but with no notable breakthroughs. As a note, we point out here that the model structures typically used, for example, in ref 22 , where model graphene clusters were utilized, have been rather unrealistic and do not really adequately represent the structural complexity of amorphous carbon and its surfaces. ${ }^{25,27-29} \mathrm{We}$ argue that one of the main reasons that the behavior of the ISR probes on nitrogenated amorphous carbon films has remained elusive is that most, if not all, of the investigations have concentrated solely on investigating the concentration and behavior of nitrogen in a-C and disregarded other atmospheric species, most notably oxygen and hydrogen. The oxygen content has frequently been measured (as in ref 22) and the $\mathrm{C} / \mathrm{O}$ ratio has been given, but the cooperative effects of $\mathrm{O}, \mathrm{H}$, and $\mathrm{N}$ have, to the best of our knowledge, never been addressed. As we will show in this Article, this appears to be the key phenomenon that can provide the so-far missing explanation for the drastically different behaviors of the OSR and ISR probes on amorphous carbon materials. Even though there exist some investigations tackling the behavior of ISR probes on oxygen-functionalized, well-defined carbon surfaces in considerable detail, ${ }^{23,30}$ these results cannot be straightfor- wardly extended for amorphous carbon surfaces, which exhibit considerably more heterogeneous and complex surface features. $^{27}$ Likewise, there exist some investigations that try to take into account detailed chemical effects induced by both $\mathrm{N}$ and $\mathrm{O}$, for instance, in the case of the reduced graphene oxide-carbon nanotube-Nafion-modified glassy carbon electrode used for the oxygen reduction reaction, but again, these results do not resonate well with the present case of nanoscale a-C thin films owing to the drastically different structures. ${ }^{31}$

Thus to fill the above stated gaps in the current knowledge, we have alloyed ta-C with nitrogen (ta-C:N) in situ by adding $\mathrm{N}_{2}(\mathrm{~g})$ to the deposition plasma of pulsed filtered cathodic arc discharge (PFCVA) to obtain thin films with three different nitrogen contents. These films have been subsequently characterized with sheet resistance measurements, atomic force microscopy (AFM), X-ray reflectivity (XRR), Raman spectroscopy, X-ray photoelectron spectroscopy (XPS), X-ray absorption spectroscopy (XAS), and time-of-flight elastic recoil detection analysis (TOF-ERDA). Furthermore, the films were electrochemically investigated by utilizing two OSR probes $\left(\mathrm{Ru}\left(\mathrm{NH}_{3}\right)_{6}{ }^{2+/ 3+}\right.$ and $\left.\mathrm{IrCl}_{6}{ }^{2-/ 3-}\right)$ and four ISR probes (DA, ascorbic acid (AA), uric acid (UA), and paracetamol (PA)) 
Table 1. Sample Naming Conventions Based on N (at \%) as Measured by TOF-ERDA, XRR Thickness, Roughness, and Density, Raman Spectroscopy $I_{\mathrm{D}} / I_{\mathrm{G}}$ Ratio, ${ }^{25}$ and AFM Roughness $R_{\mathrm{q}}(\mathrm{nm})^{a}$

\begin{tabular}{|c|c|c|c|c|c|c|}
\hline \multirow[b]{2}{*}{ sample name } & \multirow{2}{*}{$\frac{\mathrm{p}-\mathrm{FCVA}}{\mathrm{N}_{2} \text { pressure (mTorr) }}$} & \multirow{2}{*}{$\frac{\text { TOF-ERDA }}{\mathrm{N}(\text { at } \%)}$} & \multicolumn{2}{|c|}{ XRR } & \multirow{2}{*}{$\frac{\operatorname{Raman}^{25}}{I_{\mathrm{D}} / I_{\mathrm{G}}}$} & \multirow{2}{*}{$\frac{\mathrm{AFM}}{R_{\mathrm{q}}(\mathrm{nm})}$} \\
\hline & & & thickness $(\mathrm{nm})$ & density $\left(\mathrm{g} \mathrm{cm}^{-3}\right)$ & & \\
\hline ta-C & $<0.0005$ & $<0.1$ & 27.7 & 3.02 & 0.17 & 0.17 \\
\hline ta-C: $4.2 \mathrm{~N}$ & 0.01 & 4.2 & 28.6 & 2.86 & 0.26 & 0.25 \\
\hline ta-C: $5.8 \mathrm{~N}$ & 0.10 & 5.8 & 28.1 & 2.83 & 0.30 & 0.24 \\
\hline ta-C: $9.0 \mathrm{~N}$ & 1.00 & 9.0 & 28.5 & 2.73 & 0.38 & 0.21 \\
\hline
\end{tabular}

${ }^{a_{T}}$ The reference ta-C sample (no $\mathrm{N}_{2}(\mathrm{~g})$ ) was deposited under a cryo-pump below $5 \times 10^{-7}$ Torr pressure.

using cyclic voltammetry $(\mathrm{CV})$ and electrochemical impedance spectroscopy (EIS). Finally, computational results, utilizing the machine-learning (ML)-derived interatomic potential (Gaussian approximation potential (GAP)) optimized for carbon, have been exploited to rationalize structural changes in amorphous carbon films due to decreased $\mathrm{C}^{+}$ion energies in the deposition plasma, that is, increasing $\mathrm{N}_{2}(\mathrm{~g})$ pressure. ${ }^{32}$ By investigating the concentrations of all three elements $(\mathrm{O}, \mathrm{H}$, and $\mathrm{N}$ ) in the films and correlating these with the electrochemical performance, we are, for the first time, able to explain the drastic differences in the behavior of OSR and ISR probes on a-C thin-film electrodes. Because nitrogen alloying is widely used to modify the electrical and electrochemical properties of amorphous carbon and other carbonaceous nanomaterials, these cooperative chemical effects are likely to be extremely important for a wide variety of applications and materials.

\section{RESULTS AND DISCUSSION}

Physical Characterization. A summary of the XPS, Raman, TOF-ERDA, sheet resistance, XRR, and AFM results is shown in Figure 1 and Table 1. As can be seen from Figure 1a, XPS shows a clear increase in the amount of nitrogen as a function of the increased $\mathrm{N}_{2}$ partial pressure during the deposition process. What is interesting is that it also shows a marked increase in the oxygen concentration, which appears to more or less follow the increase in the $\mathrm{N}$ content until the highest $\mathrm{N}$ fraction in the films is reached. At this point, the $\mathrm{O}$ content has markedly decreased below that of $\mathrm{N}$, most likely due to the saturation of the film by N, which "blocks" the other alloying elements from accumulating in the films, at least in high quantities. To have more information about the elemental depth distribution in the films, including that of hydrogen, a TOF-ERDA investigation was carried out, and the results are summarized in Figure 1b. They clearly show the remarkable increase not only in the amount of $\mathrm{O}$ as a function of the increased $\mathrm{N}$ content but also in the amount of $\mathrm{H}$ in the films. The concentration of $\mathrm{H}$ follows the increasing $\mathrm{N}$ content very closely and reaches a maximum of $\sim 6$ at $\% \mathrm{H}$ in the bulk before decreasing again, likely due to $\mathrm{N}$ saturation effects back to the level found in reference ta-C. The sudden increase in the $\mathrm{H}$ and $\mathrm{O}$ content that follows the changes in nitrogen concentration seen here is previously unreported in the literature. The subsequent saturation effect, however, is consistent with Spaeth et al., ${ }^{33}$ who investigated ta-C:N films with $\mathrm{N}$ at $\%$ in the range from 10 to 30 at $\% \mathrm{~N}$ and reported $\mathrm{H}$ and $\mathrm{O}$ contents below 3 at \% for all samples.

By combining the rather surface-sensitive XPS analyses with TOF-ERDA, which provides elemental depth profiling throughout the whole film, as seen in Figure 2, we can obtain information from the surface and the bulk regions of the films.

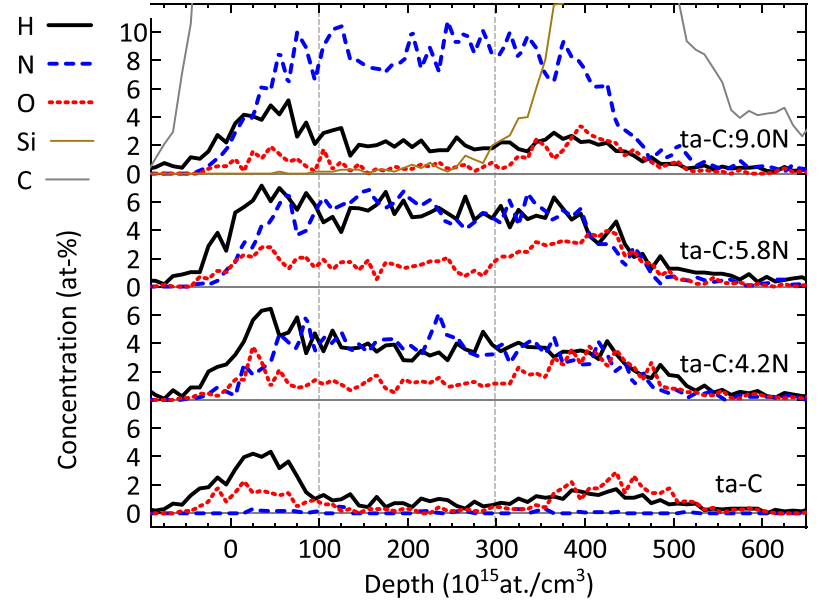

Figure 2. TOF-ERDA elemental depth profiles integrated from raw histograms displayed in Figure S5 (Supporting Information). The vertical lines show the integration area for quantitative elemental compositions shown in Figure 1 and tabulated in Table 1.

On the basis of these TOF-ERDA results, the following can be stated: (i) The overall concentrations of $\mathrm{H}$ and $\mathrm{O}$ increase with increasing $\mathrm{N}$ content both on the surface and in the bulk until saturation is reached at the $1 \mathrm{mT}$ orr $\mathrm{N}_{2}$ sample, where their concentrations drastically decrease. (ii) The $\mathrm{H}$ and $\mathrm{O}$ concentrations appear significantly higher closer to the surface of the films, which is especially notable for the reference ta-C when compared with XPS. Because the deposition chamber is pumped by a cryo pump $\left(<5 \times 10^{-7}\right.$ Torr $)$ and the reference ta-C sample contains significantly less $\mathrm{H}$ and $\mathrm{O}$, it is likely that a major origin of $\mathrm{H}$ and $\mathrm{O}$ in the films is atmospheric (most likely water vapor).

Thus when incorporating pure $\mathrm{N}$ into amorphous carbon films, one cannot ignore the role of other atmospheric species, namely, $\mathrm{O}$ and $\mathrm{H}$. This will have a major impact on the electrochemical behavior of the films, as shown later. Raman and XRR results in Figure $1 \mathrm{c}$ and Figures S2 and S3 (Supporting Information) show a steady increase in the $I_{\mathrm{D}} /$ $I_{\mathrm{G}}$ ratio, which is attributed to an increase in the carbon $\mathrm{sp}^{2}$ clustering size with added nitrogen. ${ }^{25}$ Increasing the $\mathrm{N}$ content is also correlated with the decrease in $\mathrm{sp}^{3}$ carbon bonding. ${ }^{25,34}$ This is further supported here by the clear decrease in the mass density of the film as a function of the increased $\mathrm{N}_{2}$ pressure during deposition, similar to that observed in ref 34 . Furthermore, these changes are accompanied by a major increase in the conductivity of the film, as shown in Figure 1d. Furthermore, from Table 1, it can be seen that the film thickness remains similar in all samples, whereas the density appears to slightly decrease. Thus etching of the ta-C surface by high-energy nitrogen plasma species, as suggested in ref 35 , 

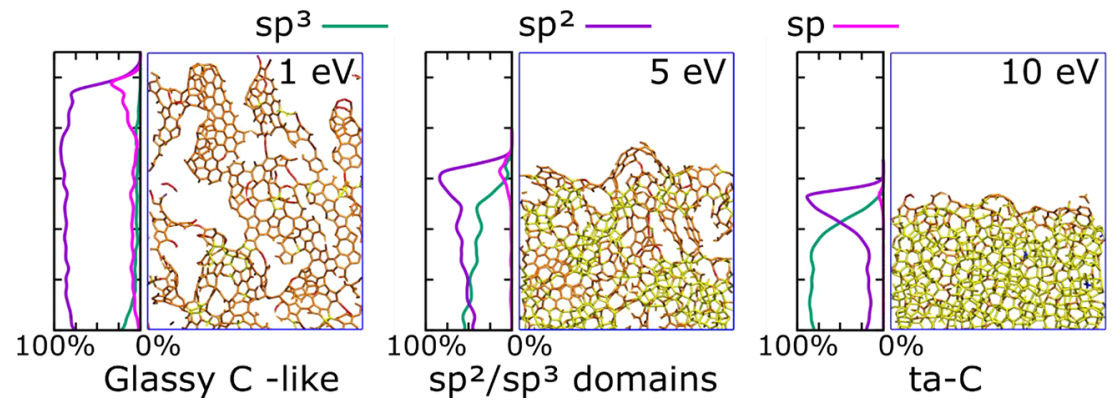

Figure 3. Atomic structure variation of a-C as a function of the carbocation incident energy. With increased energy there is a transition from ( $1 \mathrm{eV})$ graphitic glassy-like carbon to $(5 \mathrm{eV}) \mathrm{sp}^{2} / \mathrm{sp}^{3}$ clustered patch-like a-C, to $(10 \mathrm{eV}) \mathrm{sp}^{3}$-rich ta-C. The right side of each panel shows a $5 \AA$ deep slice through the simulated films reported in refs 29 and 36, where red, orange, yellow, and blue atoms indicate $\mathrm{sp}, \mathrm{sp}^{2}$, $\mathrm{sp}^{3}$, and five-fold coordinated environments, respectively. The left side shows the in-plane averaged fractions of $\mathrm{sp}, \mathrm{sp}^{2}$, and $\mathrm{sp}^{3}$ hybridization through the film thickness. The tick length for thickness is $10 \AA$ and is in scale with the right side. Mass densities in the bulk are estimated as $1.62,2.70$, and $3.30 \mathrm{~g} / \mathrm{cm}^{3}$ for 1,5 , and 10 $\mathrm{eV}$, respectively. See Figure S7 in the Supporting Information for 20 and $100 \mathrm{eV}$ deposition energies.

is not certain here because the combined changes in thickness and density are small. Finally, the surface roughness values, as measured by AFM, increase slightly, and the surface topography becomes more patch-like (Table 1, Figure S4 in the Supporting Information).

Computational Modeling of Amorphous Carbon. It can be expected that the $\mathrm{N}_{2}(\mathrm{~g})$ introduced into the plasma decreases the incident energy of the carbon ions reaching the surface, $^{32}$ as indicated by the decrease in the density and the increase in the surface roughness shown in Table 1. Samples were also deposited in argon gas, and the density trend was measured by XRR to further demonstrate this trend independent of any specific carbon-nitrogen interactions (Figure S6, Supporting Information). Because the results with Ar were consistent with those of $\mathrm{N}$, we can qualitatively utilize our recent extensive computational studies on the growth of a-C films deposited with a wide range of different energies $^{36}$ to explore the likely structural changes that this decrease in plasma energy may induce for a-C films. These simulations are based on the ML-derived interatomic potential that can provide us with close to DFT accuracy at a fraction of the computational cost. ${ }^{36-38}$ This enables us to carry out dynamic growth mechanism studies involving several thousand atoms, which is essential to capture the nonperiodic and chemically rich structure of amorphous carbon. Figure 3 shows the evolution of the a-C structure as a function of the deposition energy and the relative fractions of $\mathrm{sp}, \mathrm{sp}^{2}$, and $\mathrm{sp}^{3}$ hybridizations in the films. The $\mathrm{sp}^{3}$ fraction is positively correlated with the mass density, assuming that the films consist of low amounts of species other than carbon.

As can be seen from Figure 3, as the deposition energy decreases, the fraction of $\mathrm{sp}^{3}$-bonded carbon significantly decreases, the structure becomes less dense, and the surface roughness increases. As shown in ref 36 and on the $1 \mathrm{eV}$ panel in Figure 3, low-density films may contain a large amount of highly reactive sp-bonded carbon at the surface and less so, but still a sizable fraction, in the bulk. The sp fraction in the bulk rapidly decreases as the density (deposition energy) increases and is negligible at high deposition energies. Reactive sp motifs may remain present right at the surface; however, these can be expected to passivate in experimental samples due to (i) in situ annealing by ions and electrons, (ii) reactions with added deposition gases, and (iii) ex situ reactions with atmospheric compounds. ${ }^{27}$ Furthermore, films deposited in the range of 5 $\mathrm{eV}$ exhibited distinct regions of diamond likeness (high $\mathrm{sp}^{3}$ ) or graphite likeness (high $\mathrm{sp}^{2}$ ), making the film structure patchlike, as visible in Figure 3. In the experimental results, this patch-like surface topography is also evident in the AFM rasters (Figure S4, Supporting Information) and is consistent with what has been suggested to take place with the increase in nitrogen content in ta-C films in ref 25 . On the basis of the previous analysis, these computational studies are in qualitative agreement with XRR, Raman, and AFM results from this study and with the observations reported in the literature. ${ }^{25}$ Therefore, we can conclude that as the kinetic energy of the species reaching the film surface decreases due to collisions with nitrogen molecules in the deposition chamber, the structure of the a-C films (i) becomes less dense, (ii) exhibits a higher albeit still small surface roughness, (iii) shows clustering of the $\mathrm{sp}^{2}$-bonded carbon phase, and (iv) presents additional reactive carbon motifs that may readily form chemical bonds in situ during deposition or ex situ under atmospheric conditions. Compared with dissociated and ionized $\mathrm{N}$ species present during plasma pulses, any further in situ saturation with undissociated $\mathrm{N}_{2}$ molecules during deposition can be unfavorable at room temperature, implying a possibly nitrogen-starved deposition environment, especially for the intermediate $\mathrm{N}_{2}$ pressures of 0.01 and $0.10 \mathrm{mTorr}$. Hence subsequent exposure to the atmosphere is likely to induce the incorporation of $\mathrm{H}$ and $\mathrm{O}$ species into the structure. The comparison of the simulated depth distributions of carbon $\mathrm{sp}^{3}, \mathrm{sp}^{2}$, and $\mathrm{sp}$ in Figure 3 to elemental N, O, and $\mathrm{H}$ depth distributions observed by TOF-ERDA in Figure 2 agrees with this hypothesis.

Lastly, it is important to realize, while considering the chemical and electrochemical properties of the a-C thin films, that the surface of these films is always $\mathrm{sp}^{2}$-rich with practically identical electronic and chemical structures regardless of the amount of $\mathrm{sp}^{3}$ in the bulk of the films, as previously shown both experimentally ${ }^{39,40}$ and computationally. ${ }^{29,36}$ Whereas the thickness of this surface layer depends on the deposition energy (see Figure 3), its properties, to a large degree, do not.

Of course, the previously discussed trends remain mainly qualitative because the effect of $\mathrm{N}$ is not explicitly taken into account. However, as shown by the XPS and TOF-ERDA results, to have a realistic view of the films, one should also include $\mathrm{O}$ and $\mathrm{H}$ in these simulations in addition to $\mathrm{N}$, making the system at least a quaternary one. There is ongoing work in our groups to proceed toward these large-scale multicomponent computational studies. In the meantime, we have 

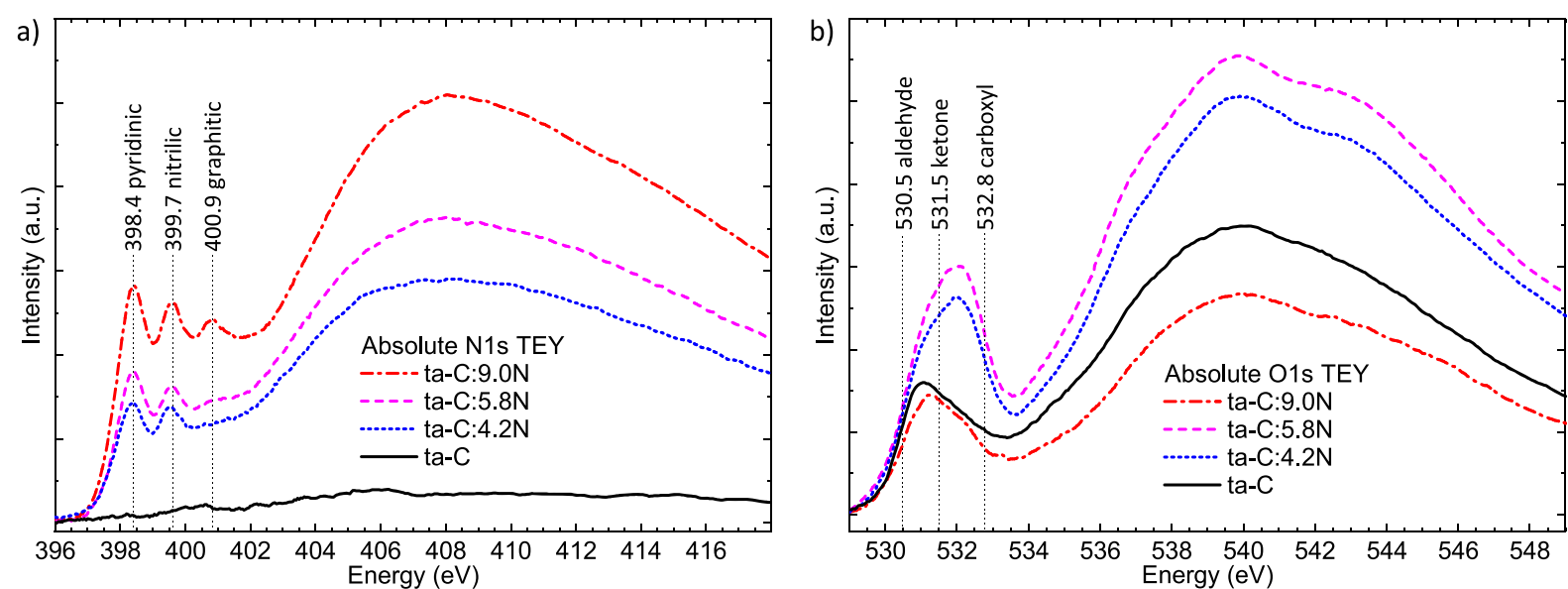

Figure 4. Absolute intensity XAS spectra in total electron yield (TEY) mode with labeled peaks for (a) N 1s spectra, ${ }^{43,44}$ and (b) O 1 s spectra. ${ }^{45,46}$ See Figures S9 and S10 in the Supporting Information for normalized spectra of C 1s, N 1s, and O 1s.

utilized computational models like those previously shown combined with the DFT level of theory to create functionalized surfaces to study the effects of various surface groups on the biomolecule adsorption in smaller scale systems. ${ }^{41}$ We will subsequently use some of these results to rationalize the electrochemical results later on.

X-ray Absorption Spectroscopy. The previous discussion summarizes the structural changes seen in ta- $\mathrm{C}$ films with the addition of nitrogen and gives information on the elemental composition of the ta-C:N films. To better understand the changes in the chemistry and bonding, specifically, further high-resolution XPS and XAS studies were carried out. It was, however, promptly noted that the high amounts of $\mathrm{N}, \mathrm{O}$, and $\mathrm{H}$ present in the films convolute the XPS high-resolution spectra, shown in Figure $\mathrm{S} 8$ in the Supporting Information. Hence, the XAS spectra of C 1s, N 1s, and $\mathrm{O} 1 \mathrm{~s}$ were inspected in an attempt to deconvolute any trends. The degree of detail provided by XAS can be higher than that of XPS because whereas XPS observes photoelectrons excited to the continuum, XAS directly probes the allowed transitions at a given energy by differentiation of the incident photon energy, making the measurement and spectra generation more direct and simpler. In this work, we utilized our extensive investigations (see Sainio et al. ${ }^{42}$ ) on the general $\mathrm{C} 1 \mathrm{~s}, \mathrm{~N} 1 \mathrm{~s}$, and $\mathrm{O} 1 \mathrm{~s}$ peak attributions for carbon nanomaterials.

The absolute and normalized intensity XAS C 1s spectra in total electron yield (TEY) mode shown in Figure S9 (Supporting Information) indicate that the major differences between the reference ta- $\mathrm{C}$ and the most heavily $\mathrm{N}$-doped ta$\mathrm{C}: 9.0 \mathrm{~N}$ film are observed in their functional groups after the $\mathrm{sp}^{2} \pi^{*}$ peak up to the carboxyl peak around $288.7 \mathrm{eV}$. In this area, one clear peak is observed at $\sim 286.7 \mathrm{eV}$, which in the literature, is often assigned for the ketone group. However, because both XPS and ERDA indicate a clear increase in the $\mathrm{N}$ content and because the same region after the $\mathrm{sp}^{2} \pi^{*}$ peak can also be assigned to carbon-nitrogen bonding, as discussed in literature, ${ }^{43,44}$ we do not believe the former interpretation to be the only correct one here. The absolute intensities of $\mathrm{N} 1 \mathrm{~s}$ and $\mathrm{O}$ 1s spectra in TEY mode shown in Figure 4 also indicate that the amount of nitrogen is continuously increased during the deposition, whereas the oxygen content seems to increase for only the intermediate steps (ta-C:4.2N and ta-C:5.8N) but is similar for the reference ta-C and ta-C:9.0N. Thus on the basis of these observations, the peak seen at $\sim 287 \mathrm{eV}$ is more likely related to the increase in $\mathrm{CN}$ bonding. Furthermore, the decrease in oxygen functional groups from the intermediate samples to the ta-C:9.0N is seen at $288.7 \mathrm{eV}$, where the carboxyl intensity is markedly decreased. Relatively minor differences between the samples were also seen in their $\mathrm{sp}^{2}$ network characterized by the $\mathrm{sp}^{2} \pi^{*}$ peak at $285.3 \mathrm{eV}$, which remained intact and did not broaden, and the changes in the peak intensities were small. The ta-C:9.0N sample with the highest nitrogen pressure during deposition had a notably higher $\mathrm{sp}^{2} \pi^{*}$ intensity than its counterparts, and some changes in the $\mathrm{sp}^{3}$ content were observed, as the reference ta- $\mathrm{C}$ had the highest and ta-C:9.0N had the lowest $\mathrm{sp}^{3}$ content. These differences were nevertheless rather subtle and hard to interpret because the $\mathrm{sp}^{3}$ content in these films is likely a result of $\mathrm{C}-\mathrm{C}, \mathrm{C}-\mathrm{O}, \mathrm{C}-\mathrm{H}$, and $\mathrm{C}-\mathrm{N}$ bonds, as also suggested in ref 35 .

Hence, to have more insight into the chemistry of the incorporated nitrogen, the absolute intensities of $\mathrm{N} 1 \mathrm{~s}$ and $\mathrm{O}$ 1s spectra were analyzed using both the TEY and the highly surface-sensitive Auger electron yield (AEY, sensitive to the first 1 to $2 \mathrm{~nm}$ of the sample surface) modes. (See the TEY in Figure 4 and the AEY in Figure 5.) They confirm the basic chemical trends already observed by TOF-ERDA and XPS. More specifically, on the basis of $\mathrm{N} 1 \mathrm{~s}$, the successive increases

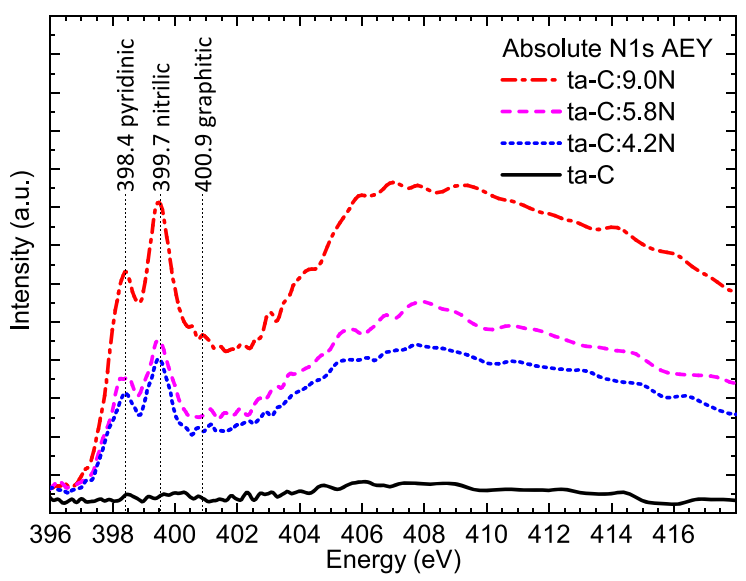

Figure 5. Absolute intensity XAS spectra in auger electron yield (AEY) mode, with labeled peaks for $\mathrm{N} 1$ s spectra. ${ }^{43,44}$ 
Table 2. EIS Results ${ }^{a}$

\begin{tabular}{|c|c|c|c|c|c|c|c|c|}
\hline \multirow[b]{2}{*}{$\mathrm{N}($ at $\%)$} & \multicolumn{4}{|c|}{ electrochemical impedance spectroscopy $5 \mathrm{mM} \mathrm{Ru}\left(\mathrm{NH}_{3}\right)_{6}$} & \multicolumn{2}{|c|}{ Nicholson's method ${ }^{63} k^{0}\left(\mathrm{~cm} \mathrm{~s}^{-1}\right)$} & \multicolumn{2}{|c|}{ Matsuda parameter ${ }^{54} \Lambda$} \\
\hline & $a$ & $R_{\mathrm{ct}}(\Omega)$ & $C_{\mathrm{dl}}\left(\mu \mathrm{F} \mathrm{cm}^{-2}\right)$ & $k^{0}\left(\mathrm{~cm} \mathrm{~s}^{-1}\right)^{64}$ & $1 \mathrm{mM} \mathrm{Ru}\left(\mathrm{NH}_{3}\right)_{6}$ & $1 \mathrm{mM} \mathrm{IrCl}_{6}$ & $1 \mathrm{mM} \mathrm{Ru}\left(\mathrm{NH}_{3}\right)_{6}$ & $1 \mathrm{mM} \mathrm{IrCl}_{6}$ \\
\hline ta-C & $0.91 \pm 0.001$ & $589.7 \pm 27.6$ & $0.33 \pm 0.01$ & $0.003 \pm 0.000$ & $0.009 \pm 0.000$ & $0.005 \pm 0.000$ & $0.7 \pm 0.0$ & $0.4 \pm 0.0$ \\
\hline taC: $4.2 \mathrm{~N}$ & $0.98 \pm 0.02$ & $5.4 \pm 0.5$ & $5.67 \pm 0.11$ & $0.28 \pm 0.03$ & $0.282 \pm 0.020$ & $0.023 \pm 0.001$ & $20.7 \pm 1.5$ & $1.7 \pm 0.1$ \\
\hline $\operatorname{taC}: 5.8 \mathrm{~N}$ & $0.97 \pm 0.02$ & $6.7 \pm 0.5$ & $5.45 \pm 0.18$ & $0.22 \pm 0.02$ & $0.222 \pm 0.036$ & $0.021 \pm 0.001$ & $15.8 \pm 2.0$ & $1.6 \pm 0.1$ \\
\hline taC: $9.0 \mathrm{~N}$ & $0.94 \pm 0.05$ & $6.3 \pm 1.0$ & $6.15 \pm 0.43$ & $0.24 \pm 0.04$ & $0.246 \pm 0.026$ & $0.028 \pm 0.002$ & $19.4 \pm 2.9$ & $2.1 \pm 0.2$ \\
\hline
\end{tabular}

${ }^{a}$ Nicholson's method rate constant $\left(k^{0}\right)$ and Matsuda parameter $(\Lambda)$ were averaged from 100, 200, 300, and $400 \mathrm{mV} / \mathrm{s}$ scan speeds. The values and errors displayed are averages and standard deviations of three measured electrodes, respectively.
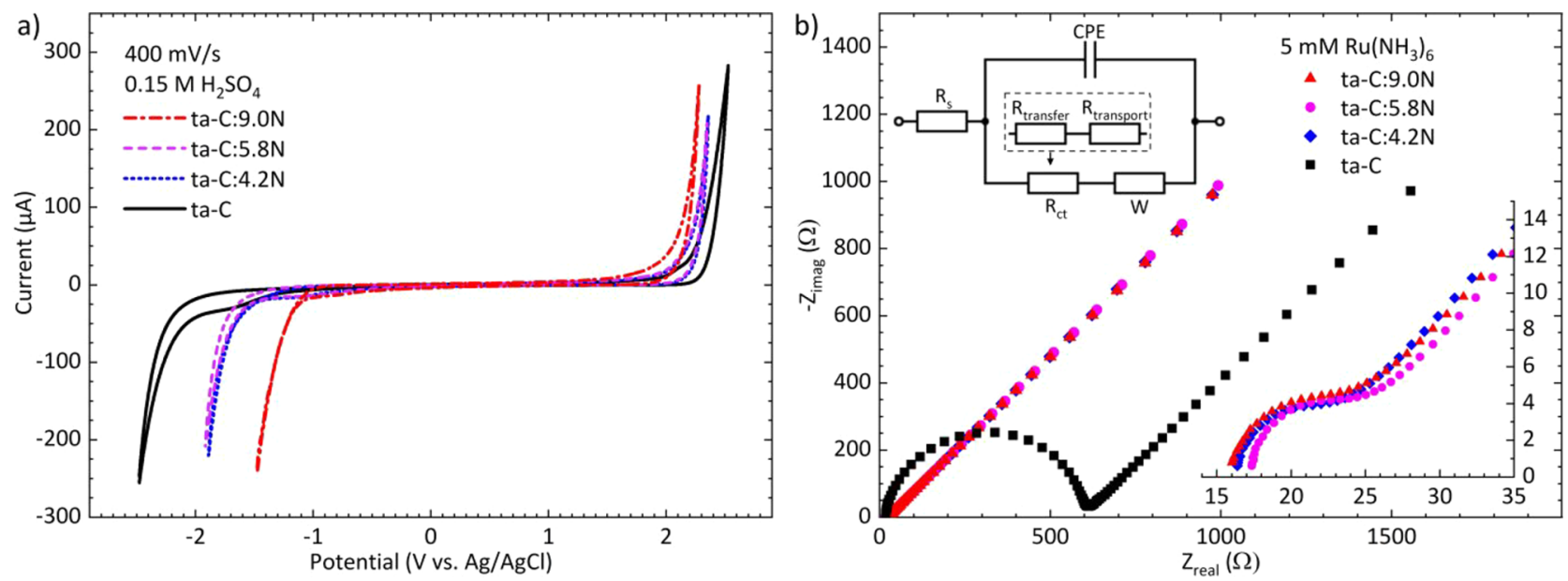

Figure 6. (a) $0.15 \mathrm{M} \mathrm{H}_{2} \mathrm{SO}_{4}$ water window cyclic voltammetry scans at $400 \mathrm{mV} / \mathrm{s}$ scan speed. (b) Nyquist plots of EIS measurements obtained in 5 $\mathrm{mM} \mathrm{Ru}\left(\mathrm{NH}_{3}\right)_{6}$ in $1 \mathrm{M} \mathrm{KCl}$ with the inset showing the high-frequency range. Results from fitting the data with the modified Randles equivalent circuit are shown in Table 2. The measurable charge-transfer resistance $R_{\mathrm{ct}}$ represents both electron transfer and transport resistances.

in the $\mathrm{N}$ content increases the pyridinic and nitrilic types of $\mathrm{CN}$ bonding for all of the ta-C:N samples. There is no direct evidence of other types of $\mathrm{CN}$ bonding (such as pyrrolic), but those cannot be completely ruled out either. Furthermore, taC:9.0N deposited at the highest $\mathrm{N}_{2}$ pressure also begins to exhibit more noticeable nitrogen substitution of carbon in graphite, that is, graphitic $\mathrm{CN}$ bonding already at room temperature. These increases in $\mathrm{CN}$ bonding observed in $\mathrm{N}$ 1s are accompanied by increased ketone and carboxyl functionals in $\mathrm{O} 1 \mathrm{~s}$ for the intermediate ta-C:4.2N and ta-C:5.8N, whereas for ta-C:9.0N, the oxygen functionalities decrease back to levels and peak shapes similar to those of the reference ta-C, as the $\mathrm{N}$ saturation presumably "blocks" elements from entering the films. The increase and the subsequent decrease in oxygen functionalities observed in $\mathrm{C} 1 \mathrm{~s}$ and $\mathrm{O} 1 \mathrm{~s}$ are in agreement with previous reports. ${ }^{45}$ Other oxygen functional groups (such as aldehydes) appear to have similar amounts through the whole data set.

Similar to the previous conjecture about a nitrogen-starved deposition environment, here we also observe two different types of $\mathrm{N}$-doping environments seemingly related to the amount of $\mathrm{N}$ during deposition. In the first system, there is an inadequate amount of $\mathrm{N}$, and the $\mathrm{N}$ bonding happens either at the edge sites of the newly formed a-C film or at the defect sites, resulting in a pyridinic or nitrilic type of bonding. More important and interesting is the second system, where a sufficient amount of $\mathrm{N}$ enables the graphitic bonding of $\mathrm{N}$ to the $\mathrm{C}$ lattice. This is potentially interesting for other doping purposes, such as with $\mathrm{N}$ doping in graphene at low temperatures.
To summarize, the Raman, XRR, and AFM results were in agreement with the changes seen in the computational structure models of a-C (Figure 3) when the deposition energy was decreased by the addition of a gas into the deposition. This approach was, however, not able to directly account for the changing amounts of $\mathrm{N}, \mathrm{O}$, and $\mathrm{H}$ content and their respective bonding configurations. The elemental composition trends observed by XPS and XAS for N, O, and $\mathrm{H}$ were in agreement with the TOF-ERDA results. Moreover, the bonding changes detected by the high-resolution XPS and XAS were less obvious owing to the serious multicomponent convolution effects induced by the presence of $\mathrm{N}, \mathrm{O}$, and $\mathrm{H}$ in the a-C. To reach an unambiguous interpretation about the nature of nitrogen and oxygen bonding in these disordered carbon films, further investigations supported by computational work are required to acquire local chemical information. Finally, it is to be noted that similar mass density changes were also evident in films deposited with Ar instead of N. This provides strong evidence that the structural changes observed in $\mathrm{a}-\mathrm{C}$, which are here linked to the subsequent alloying by atmospheric compounds, are also relevant for a wider range of disordered carbonaceous materials, even without the introduction of reactive gases, such as nitrogen, into the deposition chamber.

Electrochemical Characterization. After thorough structural and chemical analyses of the films, we proceeded to carry out electrochemical studies. Potential windows of the different ta-C:N films were measured in sulfuric acid, and the electrontransfer kinetics was studied using two different OSR probes, one with positive charge $\left(\mathrm{Ru}\left(\mathrm{NH}_{3}\right)_{6}{ }^{2+/ 3+}\right)$ and one with negative charge $\left(\mathrm{IrCl}_{6}{ }^{2-}{ }^{-}\right)$. In addition to different charge 
states, these OSR probes have very different formal potentials, around -150 and $\sim 750 \mathrm{mV}$ vs $\mathrm{Ag} / \mathrm{AgCl}$ for $\mathrm{Ru}\left(\mathrm{NH}_{3}\right)_{6}{ }^{2+/ 3+}$ and $\mathrm{IrCl}_{6}{ }^{2-/ 3-}$, respectively. This means that the surface charge of the electrode will most likely be negative in the first case and substantially positive in the second case, as the potential of zero total charge (PZTC) as measured in inert $\mathrm{HClO}_{4}$ for ta-C electrodes identical to the ones used here is $\sim 70 \mathrm{mV}$ vs $\mathrm{Ag} /$ $\mathrm{AgCl}^{47}$ Nitrogen will, of course, affect the value of PZTC to some degree, but it is not expected to shift it enormously. The use of two widely distinct probes and differently charged surfaces will thus give us a more general view of the OSR behavior in these electrodes, including possible electrostatic effects.

The electrochemical results are summarized in Table 2. Figure 6 shows the effect of $\mathrm{N}$ on the width of the potential window. As can be seen, the oxygen evolution reaction (OER) at the anodic end is not markedly influenced by the nitrogen addition, whereas the overpotential for the hydrogen evolution reaction (HER) at the cathodic end significantly decreases as nitrogen is added. The ta-C: $\mathrm{N}$ films with 4 and 6 at $\% \mathrm{~N}$ have practically identical HER onset potentials, but there is a significant decrease with further addition to 9 at $\% \mathrm{~N}$ and subsequent saturation of the films with nitrogen. This type of behavior at the cathodic end with $\mathrm{N}$ addition has been previously explained simply by the increased conductivity caused by the added nitrogen. ${ }^{18}$ However, owing to the presence of oxygen and hydrogen in the films, as shown by the XPS and TOF-ERDA results, the present case is likely not so simple. It is quite likely that the combined contributions from the $\mathrm{N}, \mathrm{H}$, and $\mathrm{O}$ affect the interaction strength of protons with the surface of the thin-film electrodes and thus the overall kinetics of the HER reaction. It has been suggested that an increased number of functional groups (both O- and N-based) on the carbon surface decreases the adsorption of $\mathrm{H}$ (in terms of both the adsorption strength and the surface coverage) from the gas phase compared with the nonfunctionalized materi$\mathrm{al}^{48,49}$ although opposite trends have also been reported. ${ }^{50}$ There are likely to be similar effects on the proton adsorption from the solution and subsequent discharge in this case. More importantly, the strong interaction of the hydrogen present in the nitrogen-doped ta-C films with the reactive $\mathrm{sp}^{2}$ surface motifs ${ }^{27}$ will also likely decrease the adsorption energy of the hydrogen from the solution side, which is often associated with increased HER activity and thus lower overpotential. ${ }^{51,52}$ The case of the highest nitrogen-containing film (ta-C:9.0N) seems to contradict the previously described trend, as it has fewer oxygen functionalities (XAS) and a lower amount of hydrogen (ERDA) compared with the other nitrogenated a-C films, and it still has the lowest overpotential for HER. However, at the same time, it also has the highest amount of $\mathrm{sp}^{2}$-bonded carbon, and it is the only film having graphitic nitrogen based on XAS, making it very different from the reference a-C and the lower nitrogen-containing films. Thus it is not straightforward to rationalize these complex phenomena, and it certainly requires further extensive experimental and computational studies, which are out of the scope of the present investigation.

The results from the CV measurements (Table 2 and Figure S11 in the Supporting Information) show that with both OSR probes, the electron-transfer kinetics increases and becomes practically reversible already with the smallest addition of $\mathrm{N}$ in comparison with pure ta-C. Heterogeneous electron-transfer constants at formal potential determined by utilizing the socalled Nicholson method ${ }^{53}$ are shown in Table 2. To obtain a further quantitative measure of the electrochemical reversibility for the different ta-C: $\mathrm{N}$ films, we also calculated the values of the parameter $\Lambda$, proposed by Matsuda and Ayabe. ${ }^{54}$ (See the Supporting Information for details.)

The results shown in Table 2 confirm that with the $\mathrm{Ru}\left(\mathrm{NH}_{3}\right)_{6}^{2+/ 3+}$ redox probe, all of the ta-C: $\mathrm{N}$ films exhibited reversible electron-transfer kinetics, and with $\mathrm{IrCl}_{6}{ }^{2-/ 3-}$, they were at the higher end of the quasireversible region. With both probes, the electron-transfer kinetics was substantially slower with the unalloyed ta-C.

The EIS measurements (Figure 6 and Table 2) done by using $\mathrm{Ru}\left(\mathrm{NH}_{3}\right)_{6}^{2+/ 3+}$ provided information that is consistent with the $\mathrm{CV}$ results, showing that the charge-transfer resistance decreased drastically with even the smallest addition of $\mathrm{N}$ and stayed approximately constant after that as nitrogen content was further increased. As was pointed out in ref 11 , the chargetransfer resistance in the case of OSR reactions on ta- $C$ films actually consists of two parts: (i) electron transfer at the electrochemical interface and (ii) electron transport through the film. (See Figure 6 for the corresponding equivalent circuit.) This is based on the fact that the surface regions of the a-C thin films are always practically identical both electronically and structurally regardless of the differences in the amount of $\mathrm{sp}^{3}$-bonded carbon in the bulk of the film. ${ }^{29,36,55}$ Therefore, the electronic coupling strength between the OSR molecule and the a-C electrode is also likely to remain unchanged. On adding nitrogen to the films, the rate constant becomes practically the same as that for the $7 \mathrm{~nm}$ thick ta-C without $\mathrm{N}$ addition reported in ref 11 , which was there taken to represent the electron-transfer resistance of ta- $\mathrm{C}$ without any additional transport contributions. Thus on the basis of this, we can expect that the increase in the reaction rate of the OSR probes is mainly caused by the increased conductivity of the films and the following decrease in the electron-transport resistance upon the addition of $\mathrm{N}$ instead of any drastic changes in the electron-transfer rates. This increased conductivity of nitrogen-doped ta-C was evident based on the sheet resistance measurements and can be computationally justified based on the increase in the density of states (DOS) of the material around the Fermi level, as previously shown by us. ${ }^{41}$ We cannot, however, completely rule out the possibility that the presence of nitrogen in the film surface region would also influence the surface DOS to a degree that it would increase the electronic coupling between the reactant and the electrode surface and thus affect the electron-transfer step. No electrostatic effects were seen despite the different charge states of the electrode surfaces during the measurements with $\mathrm{Ru}\left(\mathrm{NH}_{3}\right)_{6}^{2+/ 3+}$ and $\mathrm{IrCl}_{6}^{2-/ 3-}$. Finally, it was shown that the capacitances of the ta-C: $\mathrm{N}$ films were somewhat larger than that of ta-C, and they experienced slightly more ideal capacitive behavior, as the $a$ value was closer to one. (See Table 2.)

The electrochemical behavior was further characterized with four different ISR probes at physiological $\mathrm{pH}$ : two negatively charged probes (AA and UA), one neutral probe (PA), and one positively charged probe (DA). This was done again to assess the possible electrostatic effects in addition to specific chemical interactions. The peak potential data of the ISR probes are summarized in Figure 7. It is evident that with all of the analytes, the oxidation peak potential shifts anodically when nitrogen is incorporated into the ta-C film, implying a significant decrease in the overall rate of the reaction. Thus the behavior is completely opposite to that observed with the OSR probes. Similar phenomena for a-C thin film electrodes have 


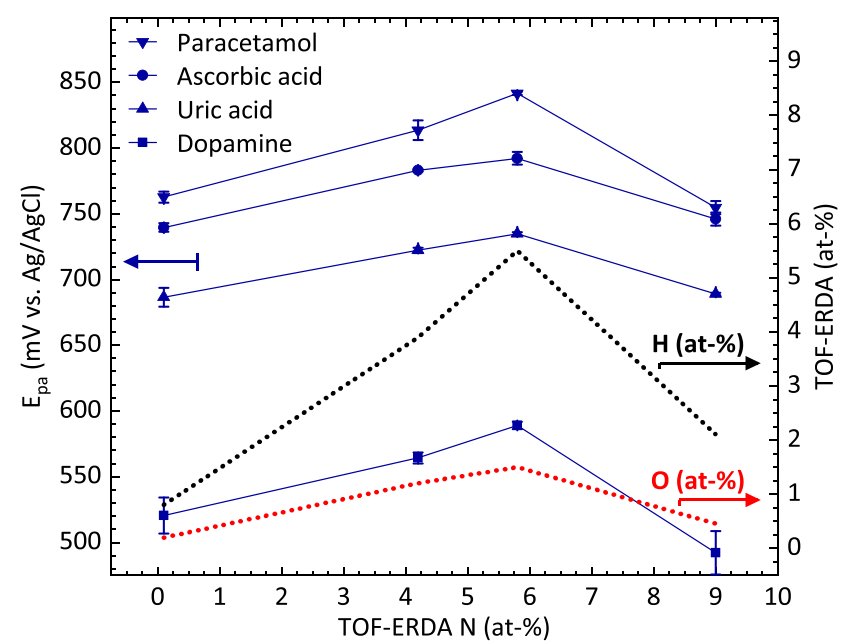

Figure 7. Inner-sphere redox (ISR) probe anodic peak potential $\left(E_{\mathrm{pa}}\right)$ at $500 \mathrm{mV} / \mathrm{s}$ scan speed as measured in PBS as a function of elemental compositions $(\mathrm{N}, \mathrm{O}, \mathrm{H})$ by TOF-ERDA. ISR probe $E_{\mathrm{pa}}$ values are shown as averages with standard deviations as error bars $(N$ $=3$ ). See Figure S13 and Table S2 in the Supporting Information for the $\mathrm{CV}$ scans and tabulated values.

also been observed, for example, in ref 23 , but they have remained unexplained until now. In contrast with the OSR probes, the ISR probes are highly surface-sensitive and often require adsorption onto the electrode surface for the reactions to occur. ${ }^{7}$ The fact that we have, in addition to nitrogen, oxygen on the sample surfaces is typically assumed to enhance the adsorption of many of the ISR probes, as is the case, for example, with DA. ${ }^{41,56}$

Our previous computational results ${ }^{41}$ indicate that the adsorption strength of DAQ which is the oxidation reaction product of DA, increases as the surface of the ta-C electrode becomes negative. This can take place, for example, because of the presence of oxygen functionalities (most notably $-\mathrm{COOH}$ and ketones) on the film surface at physiological $\mathrm{pH}$. This interaction would then result in a cathodic shift in the oxidation potential of DA on the a-C thin-film electrodes, as shown in ref 57. Likewise, AA has been shown to experience a similar cathodic shift in its oxidation potential in the presence of similar oxygen functionalities. ${ }^{39}$ Moreover, our recent investigations show that PA also experiences a cathodic shift in its oxidation potential upon oxidative treatment of singlewall carbon nanotube (SWCNT) network electrodes. ${ }^{58}$ Because an opposite trend is seen here in all of the previously discussed cases, some species other than oxygen in the system must cause this inhibition of the reaction on the nitrogenated electrode surfaces. Furthermore, the response of nitrogenated amorphous carbon films toward DA oxidation was recently investigated by Behan et al. ${ }^{23}$ Their results indicated that there was a slight increase in the oxidation current of DA (but no change in the oxidation potential) on nitrogen-containing film in comparison with nitrogen-free film: The $I_{\mathrm{p}}$ value increased linearly as a function of the scan rate, and the peaks were symmetric, pointing toward the weak adsorption of reaction species on the surface of nitrogenated a-C electrodes. The authors $^{23}$ also reported that their films contained oxygen in addition to nitrogen in a similar or slightly higher amount. The hydrogen content was not reported, but the fact that the films were annealed at $900{ }^{\circ} \mathrm{C}$ under a $\mathrm{N}_{2}$ atmosphere after deposition for $1 \mathrm{~h}$ indicated that most (if not all) of the atmospheric contaminants were removed. Finally, a cathodic shift in the oxidation peaks of AA, DA, and UA on a nitrogendoped graphene-modified glassy carbon electrode was reported by Sheng et al. ${ }^{59}$ As in the previously discussed investigation, also in this case, the nitrogen-doped graphene contained oxygen along with nitrogen, and no information about the hydrogen content was given. On the basis of the fabrication process including annealing at $800{ }^{\circ} \mathrm{C}$ under an $\mathrm{Ar}$ atmosphere, one can however, assume that the hydrogen content was at least not very significant.

Thus the fact that we have considerably high hydrogen loading in our films, as shown by TOF-ERDA (Figure 1 and 2 ), provides us at least a partial answer. Hydrogen is known to passivate, for example, boron-doped diamond (BDD) surfaces, ${ }^{60}$ and on the basis of our calculations, it exhibits a large adsorption strength on different sites on amorphous carbon surfaces. ${ }^{45}$ Thus it is expected that in this case, the large amount of hydrogen in the films passivates most of the reactive adsorption sites on the surface and subsequently reduces the kinetics of all of the investigated ISR probes. The process of surface passivation and the incorporation of atmospheric species is likely to be facilitated by the slightly more open and reactive nature of ta-C: $\mathrm{N}$ in comparison with ta-C films (see Table 1 and Figures 2 and 3), providing adsorption sites with higher energies. The logarithm of the oxidation peak current versus the log of the scanning rate for DA (Figure S12) gave a slope close to 0.5 , suggesting a diffusion-controlled process. Because adsorption is known to be required for DA reactions to take place on carbon films, this behavior is consistent with the observed strong anodic shift in the oxidation potential. ${ }^{61,62}$ Our argumentation is further supported by the fact that as shown by the TOF-ERDA results, the kinetics of all of the ISR probes are lowest with the highest hydrogen content and return to about the same level or higher than that of the reference ta- $\mathrm{C}$ electrodes with the highest nitrogen content, ta$\mathrm{C}: 9.0 \mathrm{~N}$, when the hydrogen level is pushed back down to a value similar to that in the reference ta-C electrodes (Figures 2 and 4). Moreover, because the chemically quite different ISR probes all behave identically, this tends to rule out that our observations would be caused by specific functional groups present on the surface. Together, these facts strongly suggest that hydrogen is, in fact, mainly responsible for the observed behavior, and the details of the surface chemistry revealed by XAS (and XPS) are of minor importance. Hence, regarding the answer to the question that we posed in the title of this Article, we can state: (i) OSR probes exhibit faster kinetics as they "respond" to the increased conductivity of ta-C:N films, whereas (ii) ISR probes interact with the hydrogen-passivated surface of the ta-C:N films, and subsequently, their reaction rates are decreased.

\section{CONCLUSIONS}

In this Article, we have shown that when ta- $C$ thin films are alloyed with nitrogen, one cannot ignore the presence of other dopants, such as atmospheric gases hydrogen and oxygen. By combining sheet resistance measurements, XRR, Raman spectroscopy, XPS, XAS, and TOF-ERDA we could show that as $\mathrm{N}$ is added to ta- $\mathrm{C}$ thin films, (i) the conductivity increases, (ii) the mass density decreases, (iii) the surface roughness increases, and most importantly, (iv) $\mathrm{O}$ and $\mathrm{H}$ are incorporated into the films along with N. Interestingly, nitrogen substitution of carbon in graphite was also observed for the highest $\mathrm{N}$ content. Using our recent methodology from 
extensive computational studies on a-C deposition, we could qualitatively support the hypothesis that as the addition of $\mathrm{N}_{2}(\mathrm{~g})$ into the chamber decreases the deposition incident energy, this makes the structure of a- $\mathrm{C}$ more open, clusters the carbon $\mathrm{sp}^{2}$ phase, and increases the overall reactivity (increase in the fraction of $\mathrm{sp}$ and $\mathrm{sp}^{2} \mathrm{C}$ ), resulting in the incorporation of atmospheric $\mathrm{O}$ and $\mathrm{H}$ into the films. These structural and chemical effects are used to rationalize the previously ambiguous differences in the behavior of OSR and ISR probes. We argue that the excess hydrogen in the films will passivate most of the active adsorption sites on the surface and result in a significant decrease in the kinetics of the surface-sensitive ISR probes. On the contrary, the kinetics of the surface-insensitive OSR probes increases owing to the higher conductivity of the nitrogen-alloyed ta-C:N films. Because $\mathrm{N}$ incorporation is widely used to alter the properties of disordered carbonaceous materials, these results will have a wide impact on many fields, such as advanced energy solutions and electrochemical sensing applications.

\section{EXPERIMENTAL METHODS}

All samples were deposited on boron-doped p-type silicon (100) prime wafers $(<0.005 \Omega \mathrm{cm}$, Siegert Wafer $)$ and microscope glass slides (Menzel) with a p-FCVA system in a vacuum chamber evacuated to base pressures below $5 \times 10^{-7}$ Torr using a CTI cryogenics CTI $8 \mathrm{~F}$ cryopump. The p-FCVA system uses a toroidal $45^{\circ}$ bent electromagnetic filter, with a pulse-forming network unit of $2.6 \mathrm{mF}$ charged to $-400 \mathrm{~V}$ (pulse current $650 \mathrm{~A}, 1 \mathrm{~Hz}$ ). Substrates were placed on a $17 \mathrm{rpm}$ rotating holder at room temperature. The source material for the carbon plasma was a graphite rod of $6.35 \mathrm{~mm}$ diameter and purity of $99.95 \%$ (Graphitestore). Nitrogen gas (99.9999\%) was introduced into the chamber via a mass flow controller at flow rates ranging from 14 to $71 \mathrm{sccm}$ for 0.01 to 1.00 mTorr chamber pressure, respectively. No gas was added for the reference ta-C deposition, for which the pressure remained below $5 \times$ $10^{-7}$ Torr during deposition.

XRR measurements were performed in parallel beam mode using a Rigaku SmartLab diffractometer equipped with a $9 \mathrm{~kW}$ rotating $\mathrm{Cu}$ anode $(0.154 \mathrm{~nm})$, a HyPix-3000 2D single photon counting detector, and a monochromator. A Veeco Dimension 5000 AFM was used in tapping mode with Mikromasch HQ:NSC14/Al BS tips of $8 \mathrm{~nm}$ typical tip radius and a $5 \mathrm{~N} \mathrm{~m}^{-1}$ force constant. Images were processed using Gwyddion 2.47 software for artifact correction and calculation of the root-mean-square (RMS) surface roughness $\left(R_{\mathrm{q}}\right)$. The sheet resistance was measured for glass substrate samples using a Jandel probe attached to a DC power source and a picoammeter. Raman spectroscopy was performed by a Horiba Jobin-Yvon Labram HR confocal Raman system with a $488 \mathrm{~nm}$ argon laser with $10 \mathrm{~mW}$ power on the sample. A spot size of $1 \mu \mathrm{m}$ was used with an Olympus $100 \times$ objective. Spectra were acquired in the range of 50 to 3000 $\mathrm{cm}^{-1}$ with a 600 lines/inch diffraction grating, exposure time of $15 \mathrm{~s}$, and an average count of two. Spectroscopic calibration was performed on an intrinsic Si wafer (Ultrasil). Raman spectra were fitted by two Gaussian peaks for $\mathrm{D}$ and $\mathrm{G}$ regions of amorphous carbon to obtain the $I_{\mathrm{D}} / I_{\mathrm{G}}$ peak intensity ratios, as explained in the literature. ${ }^{25}$

The a-C deposition molecular dynamics simulations, as detailed in the literature, ${ }^{29,36}$ were carried out using the GAP for the amorphous carbon of Deringer and Csányi ${ }^{38}$ by depositing one atom at a time onto a preexisting diamond substrate. The deposition of a-C films over a wide range of energies ( 1 to $100 \mathrm{eV}$ ) was simulated by throwing monoenergetic carbon atoms onto the growing film, with each impact followed by a period of equilibration to bring the system back to its nominal temperature of $300 \mathrm{~K}$. For this purpose, a NoséHoover thermostat with a time constant of $100 \mathrm{fs}$ was used, as implemented in LAMMPS. ${ }^{65}$ The QUIP code with the GAP plug-in was used to run the GAP simulation via its LAMMPS interface. All of the simulations used a variable time step to account for the disparate atomic velocities during impact (very high) and during equilibration (much smaller), with the general rule of thumb that the maximum atomic displacements per time step should not exceed $0.1 \AA$ Al. Also, the time used for the equilibration was variable, depending on the energy of the impacting atom. ( 1 ps was used for the highest energy collisions at $100 \mathrm{eV}$.) The resulting atomic structures in XYZ format, amenable to further third-party structural analysis, is freely available to the community from Zenodo in extended XYZ format. ${ }^{66}$

XPS was performed using an Axis Ultra electron spectrometer (Kratos Analytical) with monochromatic $\mathrm{Al} \mathrm{K \alpha}$ irradiation at $100 \mathrm{~W}$ under neutralization. Before the analysis, pre-evacuation was carried out overnight. High-resolution spectra of $\mathrm{C} 1 \mathrm{~s}, \mathrm{O} 1 \mathrm{~s}$, and $\mathrm{N} 1 \mathrm{~s}$ and survey spectra of three to four locations were recorded for each sample. 100\% filter paper (Whatman) was used as an in situ reference for charge correction. ${ }^{67,68}$ Elemental depth profiles were measured using a TOF-ERDA system. A detailed description of the method and apparatus can be found in the literature. ${ }^{69}$ The ion beam was a 15.315 $\mathrm{MeV}{ }^{127} \mathrm{I}^{8+}$ beam from the $1.7 \mathrm{MV}$ Pelletron accelerator at the Accelerator Laboratory of the University of Jyväskylä. The tilt angle was $20^{\circ}$ relative to the ion beam direction. Data were analyzed using Potku software. ${ }^{70}$ The soft X-ray XAS experiments were conducted at the Stanford Synchrotron Radiation Lightsource (SSRL) beamline 82 , where a bending magnet was used with a $55^{\circ}$ incidence angle (magic angle) of X-rays. A resolution of $\sim 200 \mathrm{meV}$ was achieved with a spherical grating monochromator that was operated using $40 \times 40$ $\mu \mathrm{m}$ slits. The X-ray beam spot size was $\sim 1 \times 1 \mathrm{~mm}^{2}$ with total flux on the order of 1010 photons/s. The X-ray energy for $\mathrm{N}, \mathrm{C}$, and $\mathrm{O} 1 \mathrm{~s}$ edges was measured from 380 to 440,260 to 340 , and 520 to $560 \mathrm{eV}$, respectively. A Keithley picoammeter was used to amplify the drain current to collect all of the data in TEY mode, where the incoming flux was measured using a nickel grid coated with $\mathrm{Au}$-sputtered film. Here a reference sample was used for energy calibration of the data prior to the data analysis. The $\mathrm{C} 1 \mathrm{~s}$ spectra were confirmed to match their energy calibration by observing the core-exciton signature at $291.65 \mathrm{eV}$ after the reference sample energy alignment. ${ }^{71-73}$ The N 1s spectra were energy-corrected and aligned using a $\mathrm{Ni} 2 \mathrm{p}$ signal in second order at $426.35 \mathrm{eV}$. The $\mathrm{Ni} 2 \mathrm{p}$ was available via a reference sample inserted upstream, which cut $\sim 2 \%$ of the incoming intensity. The $\mathrm{O} 1 \mathrm{~s}$ spectra were first aligned by matching their oxygen $i_{0}$ dip (roughly at $530 \mathrm{eV}$ ) and then further aligned to match the carbon tape $\mathrm{O} 1 \mathrm{~s} \pi^{*}$ to $532.0 \mathrm{eV}$. The presented $\mathrm{N} 1 \mathrm{~s}, \mathrm{C} 1 \mathrm{~s}$, and $\mathrm{O} 1 \mathrm{~s}$ spectra were averaged from three different locations. Furthermore, all of the data were background-subtracted and energy-corrected using IGOR Pro v. 8.02 software.

Electrochemical measurements were carried out inside a Faraday's cage at room temperature on a Gamry Reference 600 potentiostat and analyzed using Gamry Echem Analyst software. All values are averages of three measured electrodes. New electrodes were used for every electrochemical experiment. Both CV and EIS measurements were carried out in a three-electrode cell with a $\mathrm{Ag} / \mathrm{AgCl}(+0.199 \mathrm{~V}$ vs SHE, Radiometer Analytical) reference electrode and a platinum wire counter electrode. Aqueous solutions of $1 \mathrm{M} \mathrm{KCl}$ (Merck Suprapur) and phosphate-buffered saline (PBS) solution ( $\mathrm{pH}$ 7.4) were prepared with water from a Millipore system $(>18 \mathrm{M} \Omega \mathrm{cm})$ and were deaerated for at least 15 min with $\mathrm{N}_{2}(\mathrm{~g})$ prior to measurements. In addition, the cell was blanketed in a continuous flow of nitrogen. Electrodes were prepared by masking the samples with polytetrafluoroethylene (PTFE) tape (Saint-Gobain Performance Plastics CHR 2255-2) onto FR-4 copper laminate sheets (MG Chemicals). Uncompensated resistance $\left(R_{\mathrm{u}}\right)$ approximations were measured in the supporting electrolytes to discard poorly prepared electrodes. Hence, when measuring low currents of $\sim 10 \mu \mathrm{A}$, the ohmic drop resulting from $R_{\mathrm{u}}$ was only a few millivolts and could be disregarded. The active electrode surface area was $3 \mathrm{~mm}$ in diameter, equating to $0.07 \mathrm{~cm}^{2}$. The potential windows were determined in $0.15 \mathrm{M} \mathrm{H}_{2} \mathrm{SO}_{4}$ (Merck Suprapur) by cycling at a scan rate of $400 \mathrm{mV} / \mathrm{s}$ starting from the reference potential, so that the absolute values of both the anodic and the cathodic current were $\sim 200 \mu \mathrm{A}$. CV measurements in $1 \mathrm{mM}$ $\mathrm{Ru}\left(\mathrm{NH}_{3}\right)_{6}$ (hexaammineruthenium(III) chloride, Sigma-Aldrich) and $1 \mathrm{mM} \mathrm{IrCl} 6$ (potassium hexachloroiridate(IV), Sigma-Aldrich) 
dissolved in $1 \mathrm{M} \mathrm{KCl}$ (Sigma-Aldrich) were performed at scanning rates of $25,50,100,200,300,400$, and $500 \mathrm{mV} / \mathrm{s}$, of which only the $500 \mathrm{mV} / \mathrm{s}$ measurements are shown here. The CV of the inner-sphere analytes $1 \mathrm{mM}$ PA (Sigma-Aldrich), $1 \mathrm{mM}$ AA (Sigma-Aldrich), 1 mM UA (Sigma-Aldrich), and $0.1 \mathrm{mM} \mathrm{DA} \mathrm{(Sigma-Aldrich)} \mathrm{was}$ similarly performed in PBS. EIS measurements were conducted in 5 $\mathrm{mM} \mathrm{Ru}\left(\mathrm{NH}_{3}\right)_{6}$ dissolved in $1 \mathrm{M} \mathrm{KCl}$. An AC signal of $15 \mathrm{mV}$ in amplitude was used in the frequency range from $200 \mathrm{kHz}$ to 100 $\mathrm{mHz}$. CV measurements at $400 \mathrm{mV} / \mathrm{s}$ were used to determine the formal potentials of the $\mathrm{Ru}\left(\mathrm{NH}_{3}\right)_{6}{ }^{3+/ 2+}$ redox system, which were set as the DC potentials for EIS. The obtained EIS spectra were fitted and analyzed using Gamry Echem Analyst software. The equivalent circuit used for fitting the Nyquist plots was a modified Randles circuit $^{11}$ with a solution resistance $\left(R_{\mathrm{s}}\right)$ in series with a parallel circuit of a charge-transfer resistance $\left(R_{\mathrm{ct}}\right)$ element, an infinite Warburg element, and a constant-phase element (CPE) for the double-layer capacitance $\left(C_{\mathrm{dl}}\right)$. The $R_{\mathrm{ct}}$ element comprised two resistance elements: electron transfer to the film surface and electron transport through the film. For the $C_{\mathrm{d} l}$, the ideal capacitor parameter $(a=1$ for an ideal capacitor) and the apparent heterogeneous rate constant $\left(k^{0}\right)$ were calculated as described by Hsu and Mansfeld. ${ }^{64}$ Nicholson's method ${ }^{63}$ was used to calculate rate constants $k^{0}$ from $100,200,300$, and 400 $\mathrm{mV} / \mathrm{s}$ scan rates for $1 \mathrm{mM} \mathrm{Ru}\left(\mathrm{NH}_{3}\right)_{6}$ in $1 \mathrm{M} \mathrm{KCl}$ and $1 \mathrm{mM} \mathrm{IrCl}_{6}$ in $1 \mathrm{M} \mathrm{KCl}$. Matsuda parameters were calculated from these $k^{0}$ values, as described in ref 54

\section{ASSOCIATED CONTENT}

\section{(s) Supporting Information}

The Supporting Information is available free of charge at https://pubs.acs.org/doi/10.1021/acs.chemmater.1c01519.

Raman spectra, XRR scans, AFM rasters, wide and highresolution XPS results, TOF-ERDA histograms and fulldepth profiles, XRR thickness and density results of ta-C films deposited in argon atmospheres, computational modeling of amorphous carbon growth at 20 and $100 \mathrm{eV}$ deposition energies using machine-learning-derived interatomic potentials, normalized and absolute intensity XAS for $\mathrm{C} 1 \mathrm{~s}, \mathrm{~N} 1 \mathrm{~s}$, and $\mathrm{O} 1 \mathrm{~s}, \mathrm{CV}$ results for OSR probes, $\mathrm{Ru}\left(\mathrm{NH}_{3}\right)_{6}$, and $\mathrm{IrCl}_{6}$, and for ISR probes, PA, $\mathrm{AA}, \mathrm{UA}$, and DA (PDF)

\section{AUTHOR INFORMATION}

\section{Corresponding Author}

Tomi Laurila - Department of Electrical Engineering and Automation, School of Electrical Engineering, Aalto University, 02150 Espoo, Finland; 10 orcid.org/0000-00021252-8764; Email: tomi.laurila@aalto.fi

\section{Authors}

Jarkko Etula - Department of Chemistry and Materials Science, School of Chemical Engineering, Aalto University, 02150 Espoo, Finland; (1) orcid.org/0000-0002-6930-1165

Niklas Wester - Department of Chemistry and Materials Science, School of Chemical Engineering, Aalto University, 02150 Espoo, Finland; 10 orcid.org/0000-0002-7937-9011

Touko Liljeström - Department of Chemistry and Materials Science, School of Chemical Engineering, Aalto University, 02150 Espoo, Finland

Sami Sainio - Stanford Synchrotron Radiation Lightsource, SLAC National Accelerator Laboratory, Menlo Park, California 94025, United States; Microelectronics Research Unit, Faculty of Information Technology and Electrical Engineering, University of Oulu, $90570 \mathrm{Oulu}$, Finland
Tommi Palomäki - Department of Chemistry and Materials Science, School of Chemical Engineering, Aalto University, 02150 Espoo, Finland

Kai Arstila - Department of Physics, University of Jyväskylä, 40500 Jyväskylä, Finland

Timo Sajavaara - Department of Physics, University of Jyväskylä, 40500 Jyväskylä, Finland

Jari Koskinen - Department of Chemistry and Materials Science, School of Chemical Engineering, Aalto University, 02150 Espoo, Finland

Miguel A. Caro - Department of Electrical Engineering and Automation, School of Electrical Engineering, Aalto University, 02150 Espoo, Finland; o orcid.org/0000-00019304-4261

Complete contact information is available at:

https://pubs.acs.org/10.1021/acs.chemmater.1c01519

\section{Notes}

The authors declare no competing financial interest.

\section{ACKNOWLEDGMENTS}

We acknowledge the provision of facilities by RawMatters Finland Infrastructure (RAMI, no. 292884), Aalto University Bioeconomy, and OtaNano - Nanomicroscopy Center (AaltoNMC). Use of the Stanford Synchrotron Radiation Lightsource, SLAC National Accelerator Laboratory, is supported by the U.S. Department of Energy, Office of Science, Office of Basic Energy Sciences under contract no. DE-AC0276SF00515. We acknowledge CSC - IT Center for Science, Finland, for computational resources. S.S. acknowledges funding from the Walter Ahlström Foundation. This project has received funding from the European Union's Horizon 2020 research and innovation programme under the Marie Skłodowska-Curie grant agreement no. 841621 and the Business Finland FEPOD 2117731 project. M.A.C. acknowledges funding from the Academy of Finland under project number 30488 .

\section{REFERENCES}

(1) Laurila, T.; Sainio, S.; Caro, M. A. Hybrid Carbon Based Nanomaterials for Electrochemical Detection of Biomolecules. Prog. Mater. Sci. 2017, 88, 499-594.

(2) Laurila, T.; Protopopova, V.; Rhode, S.; Sainio, S.; Palomäki, T.; Moram, M.; Feliu, J. M.; Koskinen, J. New Electrochemically Improved Tetrahedral Amorphous Carbon Films for Biological Applications. Diamond Relat. Mater. 2014, 49, 62-71.

(3) Aigaje Espinosa, E. K.; Qiu, J.; Jarošová, R.; Castiaux, A.; Swain, G. M. HPLC-EC Analysis of Estrogenic Compounds: A Comparison of Diamond and Tetrahedral Amorphous Carbon Electrode Performance. Electroanalysis 2018, 30 (7), 1575-1582.

(4) Yoo, K.; Miller, B.; Kalish, R.; Shi, X. Electrodes of NitrogenIncorporated Tetrahedral Amorphous Carbon. A Novel Thin-Film Electrocatalytic Material with Diamond-like Stability. Electrochem. Solid-State Lett. 1999, 2 (5), 233-235.

(5) Jarošová, R.; De Sousa Bezerra, P. M.; Munson, C.; Swain, G. M. Assessment of Heterogeneous Electron-Transfer Rate Constants for Soluble Redox Analytes at Tetrahedral Amorphous Carbon, BoronDoped Diamond, and Glassy Carbon Electrodes. Phys. Status Solidi A 2016, 213 (8), 2087-2098.

(6) Protopopova, V. S.; Wester, N.; Caro, M. A.; Gabdullin, P. G.; Palomäki, T.; Laurila, T.; Koskinen, J. Ultrathin Undoped Tetrahedral Amorphous Carbon Films: Thickness Dependence of the Electronic Structure and Implications for Their Electrochemical Behaviour. Phys. Chem. Chem. Phys. 2015, 17 (14), 9020-9031. 
(7) Palomäki, T.; Chumillas, S.; Sainio, S.; Protopopova, V.; Kauppila, M.; Koskinen, J.; Climent, V.; Feliu, J. M.; Laurila, T. Electrochemical Reactions of Catechol, Methylcatechol and Dopamine at Tetrahedral Amorphous Carbon ( $\mathrm{Ta}-\mathrm{C})$ Thin Film Electrodes. Diamond Relat. Mater. 2015, 59, 30-39.

(8) Viswanathan, S.; Manjunath Reddy, M.; Mohan, L.; Bera, P.; Barshilia, H. C.; Anandan, C. Corrosion and Wear Properties of Ti/ Tetrahedral Amorphous Carbon Multilayered Coating. J. Bio- TriboCorrosion 2017, 3 (3), 39.

(9) Sainio, S.; Palomäki, T.; Tujunen, N.; Protopopova, V.; Koehne, J.; Kordas, K.; Koskinen, J.; Meyyappan, M.; Laurila, T. Integrated Carbon Nanostructures for Detection of Neurotransmitters. Mol. Neurobiol. 2015, 52 (2), 859-866.

(10) Sainio, S.; Leppänen, E.; Mynttinen, E.; Palomäki, T.; Wester, N.; Etula, J.; Isoaho, N.; Peltola, E.; Koehne, J.; Meyyappan, M.; Koskinen, J.; Laurila, T. Integrating Carbon Nanomaterials with Metals for Bio-Sensing Applications. Mol. Neurobiol. 2020, 57 (1), 179-190.

(11) Palomäki, T.; Wester, N.; Caro, M. A.; Sainio, S.; Protopopova, V.; Koskinen, J.; Laurila, T. Electron Transport Determines the Electrochemical Properties of Tetrahedral Amorphous Carbon (TaC) Thin Films. Electrochim. Acta 2017, 225, 1-10.

(12) Veerasamy, V. S.; Yuan, J.; Amaratunga, G. A. J.; Milne, W. I.; Gilkes, K. W. R.; Weiler, M.; Brown, L. M. Nitrogen Doping of Highly Tetrahedral Amorphous Carbon. Phys. Rev. B: Condens. Matter Mater. Phys. 1993, 48 (24), 17954-17959.

(13) Robertson, J.; Davis, C. A. Nitrogen Doping of Tetrahedral Amorphous Carbon. Diamond Relat. Mater. 1995, 4 (4), 441-444.

(14) Kleinsorge, B.; Ferrari, A. C.; Robertson, J.; Milne, W. I.; Waidmann, S.; Hearne, S. Bonding Regimes of Nitrogen in Amorphous Carbon. Diamond Relat. Mater. 2000, 9 (3), 643-648.

(15) Yang, X.; Haubold, L.; DeVivo, G.; Swain, G. M. Electroanalytical Performance of Nitrogen-Containing Tetrahedral Amorphous Carbon Thin-Film Electrodes. Anal. Chem. 2012, 84 (14), 6240-6248.

(16) Jarošová, R.; Rutherford, J.; Swain, G. M. Evaluation of a Nitrogen-Incorporated Tetrahedral Amorphous Carbon Thin Film for the Detection of Tryptophan and Tyrosine Using Flow Injection Analysis with Amperometric Detection. Analyst 2016, 141 (21), 6031-6041.

(17) Brocenschi, R. F.; Rocha-Filho, R. C.; Li, L.; Swain, G. M. Comparative Electrochemical Response of Estrone at Glassy-Carbon, Nitrogen-Containing Tetrahedral Amorphous Carbon and BoronDoped Diamond Thin-Film Electrodes. J. Electroanal. Chem. 2014, $712,207-214$.

(18) Khun, N. W.; Liu, E.; Guo, H. W. Cyclic Voltammetric Behavior of Nitrogen-Doped Tetrahedral Amorphous Carbon Films Deposited by Filtered Cathodic Vacuum Arc. Electroanalysis 2008, 20 (17), 1851-1856.

(19) Sopchak, D.; Miller, B.; Kalish, R.; Avyigal, Y.; Shi, X. Dopamine and Ascorbate Analysis at Hydrodynamic Electrodes of Boron Doped Diamond and Nitrogen Incorporated Tetrahedral Amorphous Carbon. Electroanalysis 2002, 14 (7-8), 473-478.

(20) Yee, N. C.; Shi, Q.; Cai, W.-B.; Scherson, D. A.; Miller, B. Electrochemical Characterization of Nitrogen-Incorporated Tetrahedral Carbon Films Grown by a Filtered Cathodic Vacuum Arc. Electrochem. Solid-State Lett. 2001, 4 (10), E42.

(21) Behan, J. A.; Iannaci, A.; Domínguez, C.; Stamatin, S. N.; Hoque, M. K.; Vasconcelos, J. M.; Perova, T. S.; Colavita, P. E. Electrocatalysis of N-Doped Carbons in the Oxygen Reduction Reaction as a Function of PH: N-Sites and Scaffold Effects. Carbon 2019, 148, 224-230.

(22) Behan, J. A.; Mates-Torres, E.; Stamatin, S. N.; Domínguez, C.; Iannaci, A.; Fleischer, K.; Hoque, M. K.; Perova, T. S.; GarcíaMelchor, M.; Colavita, P. E. Untangling Cooperative Effects of Pyridinic and Graphitic Nitrogen Sites at Metal-Free N-Doped Carbon Electrocatalysts for the Oxygen Reduction Reaction. Small 2019, 15 (48), 1902081.
(23) Behan, J. A.; Stamatin, S. N.; Hoque, M. K.; Ciapetti, G.; Zen, F.; Esteban-Tejeda, L.; Colavita, P. E. Combined Optoelectronic and Electrochemical Study of Nitrogenated Carbon Electrodes. J. Phys. Chem. C 2017, 121 (12), 6596-6604.

(24) Valladares, A. A.; Alvarez-Ramírez, F. Bonding in Amorphous Carbon-Nitrogen Alloys: A First Principles Study. Phys. Rev. B: Condens. Matter Mater. Phys. 2006, 73 (2), No. 024206.

(25) Ferrari, A. C.; Rodil, S. E.; Robertson, J. Interpretation of Infrared and Raman Spectra of Amorphous Carbon Nitrides. Phys. Rev. B: Condens. Matter Mater. Phys. 2003, 67 (15), 155306.

(26) Fedders, P. A.; Drabold, D.; Stumm, P. Theoretical Studies of Defects and Nitrogen Doping in Tetrahedral Amorphous Carbon. J. Non-Cryst. Solids 1998, 227-230 (PART 1), 588-593.

(27) Caro, M. A.; Aarva, A.; Deringer, V. L.; Csányi, G.; Laurila, T. Reactivity of Amorphous Carbon Surfaces: Rationalizing the Role of Structural Motifs in Functionalization Using Machine Learning. Chem. Mater. 2018, 30 (21), 7446-7455.

(28) Deringer, V. L.; Caro, M. A.; Jana, R.; Aarva, A.; Elliott, S. R.; Laurila, T.; Csányi, G.; Pastewka, L. Computational Surface Chemistry of Tetrahedral Amorphous Carbon by Combining Machine Learning and Density Functional Theory. Chem. Mater. 2018, 30 (21), 7438-7445.

(29) Caro, M. A.; Deringer, V. L.; Koskinen, J.; Laurila, T.; Csányi, G. Growth Mechanism and Origin of High Sp3 Content in Tetrahedral Amorphous Carbon. Phys. Rev. Lett. 2018, 120 (16), 166101.

(30) Patel, A. N.; Tan, S.; Miller, T. S.; Macpherson, J. V.; Unwin, P. R. Comparison and Reappraisal of Carbon Electrodes for the Voltammetric Detection of Dopamine. Anal. Chem. 2013, 85 (24), 11755-11764.

(31) Wu, K. H.; Wang, D. W.; Zong, X.; Zhang, B.; Liu, Y.; Gentle, I. $\mathrm{R}$; Su, D. S. Functions in Cooperation for Enhanced Oxygen Reduction Reaction: The Independent Roles of Oxygen and Nitrogen Sites in Metal-Free Nanocarbon and Their Functional Synergy. J. Mater. Chem. A 2017, 5 (7), 3239-3248.

(32) Kleinsorge, B.; Ferrari, A. C.; Robertson, J.; Milne, W. I. Influence of Nitrogen and Temperature on the Deposition of Tetrahedrally Bonded Amorphous Carbon. J. Appl. Phys. 2000, 88 (2), 1149-1157.

(33) Spaeth, C.; Kühn, M.; Kreissig, U.; Richter, F. Preparation of CNx Films by Ion Beam Assisted Filtered Cathodic Arc Deposition. Diamond Relat. Mater. 1997, 6 (5-7), 626-630.

(34) Polo, M. C.; Andújar, J. L.; Hart, A.; Robertson, J.; Milne, W. I. Preparation of Tetrahedral Amorphous Carbon Films by Filtered Cathodic Vacuum Arc Deposition. Diamond Relat. Mater. 2000, 9 (3), $663-667$.

(35) Rodil, S. E.; Morrison, N. A.; Robertson, J.; Milne, W. I. Nitrogen Incorporation into Tetrahedral Hydrogenated Amorphous Carbon. Phys. status solidi 1999, 174 (1), 25-37.

(36) Caro, M. A.; Csányi, G.; Laurila, T.; Deringer, V. L. Machine Learning Driven Simulated Deposition of Carbon Films: From LowDensity to Diamondlike Amorphous Carbon. Phys. Rev. B: Condens. Matter Mater. Phys. 2020, 102 (17), 174201.

(37) Bartók, A. P.; Payne, M. C.; Kondor, R.; Csányi, G. Gaussian Approximation Potentials: The Accuracy of Quantum Mechanics, without the Electrons. Phys. Rev. Lett. 2010, 104 (13), 1-4.

(38) Deringer, V. L.; Csányi, G. Machine Learning Based Interatomic Potential for Amorphous Carbon. Phys. Rev. B: Condens. Matter Mater. Phys. 2017, 95 (9), No. 094203.

(39) Sainio, S.; Nordlund, D.; Caro, M. A.; Gandhiraman, R.; Koehne, J.; Wester, N.; Koskinen, J.; Meyyappan, M.; Laurila, T. Correlation between $\mathrm{Sp} 3$-to-Sp 2 Ratio and Surface Oxygen Functionalities in Tetrahedral Amorphous Carbon (Ta-C) Thin Film Electrodes and Implications of Their Electrochemical Properties. J. Phys. Chem. C 2016, 120 (15), 8298-8304.

(40) Davis, C. A.; Amaratunga, G. A. J.; Knowles, K. M. Growth Mechanism and Cross-Sectional Structure of Tetrahedral Amorphous Carbon Thin Films. Phys. Rev. Lett. 1998, 80 (15), 3280-3283. 
(41) Aarva, A.; Laurila, T.; Caro, M. A. Doping as a Means to Probe the Potential Dependence of Dopamine Adsorption on Carbon-Based Surfaces: A First-Principles Study. J. Chem. Phys. 2017, 146 (23), 234704.

(42) Sainio, S.; Wester, N.; Aarva, A.; Titus, C. J.; Nordlund, D.; Kauppinen, E. I.; Leppänen, E.; Palomäki, T.; Koehne, J. E.; Pitkänen, O.; Kordas, K.; Kim, M.; Lipsanen, H.; Mozetič, M.; Caro, M. A.; Meyyappan, M.; Koskinen, J.; Laurila, T. Trends in Carbon, Oxygen, and Nitrogen Core in the X-Ray Absorption Spectroscopy of Carbon Nanomaterials: A Guide for the Perplexed. J. Phys. Chem. C 2021, 125 (1), 973-988.

(43) Ripalda, J. M.; Román, E.; Galán, L.; Montero, I.; Lizzit, S.; Baraldi, A.; Comelli, G.; Paolucci, G.; Goldoni, A. Core Level Spectra of Amorphous Carbon Nitride. J. Chem. Phys. 2003, 118 (8), 37483755.

(44) Schiros, T.; Nordlund, D.; Pálová, L.; Prezzi, D.; Zhao, L.; Kim, K. S.; Wurstbauer, U.; Gutiérrez, C.; Delongchamp, D.; Jaye, C.; Fischer, D.; Ogasawara, H.; Pettersson, L. G. M.; Reichman, D. R.; Kim, P.; Hybertsen, M. S.; Pasupathy, A. N. Connecting Dopant Bond Type with Electronic Structure in N-Doped Graphene. Nano Lett. 2012, 12 (8), 4025-4031.

(45) Aarva, A.; Deringer, V. L.; Sainio, S.; Laurila, T.; Caro, M. A. Understanding X-Ray Spectroscopy of Carbonaceous Materials by Combining Experiments, Density Functional Theory, and Machine Learning. Part I: Fingerprint Spectra. Chem. Mater. 2019, 31 (22), 9243-9255.

(46) Sainio, S.; Wester, N.; Aarva, A.; Titus, C. J.; Nordlund, D.; Kauppinen, E. I.; Leppänen, E.; Palomäki, T.; Koehne, J. E.; Pitkänen, O.; Kordas, K.; Kim, M.; Lipsanen, H.; Mozetič, M.; Caro, M. A.; Meyyappan, M.; Koskinen, J.; Laurila, T. Trends in Carbon, Oxygen, and Nitrogen Core in the X-Ray Absorption Spectroscopy of Carbon Nanomaterials: A Guide for the Perplexed. J. Phys. Chem. C 2021, 125 (1), 973-988.

(47) Leppänen, E.; Akhoudian, M.; Laurila, T. To be submitted/ submitted data, 2021.

(48) Zhao, X. B.; Xiao, B.; Fletcher, A. J.; Thomas, K. M. Hydrogen Adsorption on Functionalized Nanoporous Activated Carbons. J. Phys. Chem. B 2005, 109 (18), 8880-8888.

(49) Takagi, H.; Hatori, H.; Yamada, Y.; Matsuo, S.; Shiraishi, M. Hydrogen Adsorption Properties of Activated Carbons with Modified Surfaces. J. Alloys Compd. 2004, 385 (1-2), 257-263.

(50) Luo, D.; Zhang, X. The Effect of Oxygen-Containing Functional Groups on the $\mathrm{H} 2$ Adsorption of Graphene-Based Nanomaterials: Experiment and Theory. Int. J. Hydrogen Energy 2018, 43 (11), 5668-5679.

(51) Dubouis, N.; Grimaud, A. The Hydrogen Evolution Reaction: From Material to Interfacial Descriptors. Chem. Sci. 2019, 10 (40), 9165-9181.

(52) Zheng, J.; Sheng, W.; Zhuang, Z.; Xu, B.; Yan, Y. Universal Dependence of Hydrogen Oxidation and Evolution Reaction Activity of Platinum-Group Metals on PH and Hydrogen Binding Energy. Sci. Adv. 2016, 2 (3), No. e1501602.

(53) Nicholson, R. S. Theory and Application of Cyclic Voltammetry for Measurement of Electrode Reaction Kinetics. Anal. Chem. 1965, 37 (11), 1351-1355.

(54) Matsuda, H.; Ayabe, Y. Theoretical Analysis of Polarographic Waves. I. Reduction of Simple Metal Ions. Bull. Chem. Soc. Jpn. 1955, 28 (6), 422-428.

(55) Laurila, T.; Caro, M. A. Special Features of the Electrochemistry of Undoped Tetrahedral Amorphous Carbon (Ta-C) Thin Films. Encyclopedia of Interfacial Chemistry 2018, 856-862.

(56) McCreery, R. L. Advanced Carbon Electrode Materials for Molecular Electrochemistry. Chem. Rev. 2008, 108 (7), 2646-2687.

(57) Leppänen, E.; Aarva, A.; Sainio, S.; Caro, M. A.; Laurila, T. Connection between the Physicochemical Characteristics of Amorphous Carbon Thin Films and Their Electrochemical Properties. J. Phys.: Condens. Matter 2021, 33, 434002.

(58) Leppänen, E.; Sainio, S.; Jiang, H.; Mikladal, B.; Varjos, I.; Laurila, T. Effect of Electrochemical Oxidation on Physicochemical
Properties of Fe-Containing Single-Walled Carbon Nanotubes. ChemElectroChem 2020, 7 (19), 4136-4143.

(59) Sheng, Z.-H.; Zheng, X.-Q.; Xu, J.-Y.; Bao, W.-J.; Wang, F.-B.; Xia, X.-H. Electrochemical Sensor Based on Nitrogen Doped Graphene: Simultaneous Determination of Ascorbic Acid, Dopamine and Uric Acid. Biosens. Bioelectron. 2012, 34 (1), 125-131.

(60) Hoffmann, R.; Kriele, A.; Obloh, H.; Hees, J.; Wolfer, M.; Smirnov, W.; Yang, N.; Nebel, C. E. Electrochemical Hydrogen Termination of Boron-Doped Diamond. Appl. Phys. Lett. 2010, 97 (5), No. 052103.

(61) DuVall, S. H.; McCreery, R. L. Self-Catalysis by Catechols and Quinones during Heterogeneous Electron Transfer at Carbon Electrodes. J. Am. Chem. Soc. 2000, 122 (28), 6759-6764.

(62) DuVall, S. H.; McCreery, R. L. Control of Catechol and Hydroquinone Electron-Transfer Kinetics on Native and Modified Glassy Carbon Electrodes. Anal. Chem. 1999, 71 (20), 4594-4602.

(63) Nicholson, R. S. Theory and Application of Cyclic Voltammetry for Measurement of Electrode Reaction Kinetics. Anal. Chem. 1965, 37 (11), 1351-1355.

(64) Hsu, C. H.; Mansfeld, F. Technical Note: Concerning the Conversion of the Constant Phase Element Parameter Y 0 into a Capacitance. Corrosion 2001, 57 (9), 747-748.

(65) Plimpton, S. Fast Parallel Algorithms for Short-Range Molecular Dynamics. J. Comput. Phys. 1995, 117 (1), 1-19.

(66) Caro, M. A. Amorphous Carbon Films Generated through Simulated Deposition with GAP from $1 \mathrm{eV}$ to $100 \mathrm{eV}$ [Data set]. Zenodo 2020, DOI: 10.5281/zenodo.3778153. https://zenodo.org/ record/3778153\#.YPRMFkxjSUk (accessed 2021-07-19).

(67) Johansson, L.; Campbell, J. M.; Rojas, O. J. Cellulose as the in Situ Reference for Organic XPS. Why? Because It Works. Surf. Interface Anal. 2020, 52 (12), 1134-1138.

(68) Johansson, L.-S.; Campbell, J. M.; Fardim, P.; Hultén, A. H.; Boisvert, J.-P.; Ernstsson, M. An XPS Round Robin Investigation on Analysis of Wood Pulp Fibres and Filter Paper. Surf. Sci. 2005, 584 (1), 126-132.

(69) Laitinen, M.; Rossi, M.; Julin, J.; Sajavaara, T. Time-of-Flight Energy Spectrometer for Elemental Depth Profiling - Jyväskylä Design. Nucl. Instrum. Methods Phys. Res., Sect. B 2014, 337, 55-61.

(70) Arstila, K.; Julin, J.; Laitinen, M. I.; Aalto, J.; Konu, T.; Kärkkäinen, S.; Rahkonen, S.; Raunio, M.; Itkonen, J.; Santanen, J.-P.; Tuovinen, T.; Sajavaara, T. Potku - New Analysis Software for Heavy Ion Elastic Recoil Detection Analysis. Nucl. Instrum. Methods Phys. Res., Sect. B 2014, 331, 34-41.

(71) Brühwiler, P. A.; Maxwell, A. J.; Puglia, C.; Nilsson, A.; Andersson, S.; Mårtensson, N. $\mathrm{Pi}^{*}$ and Sigma* Excitons in C $1 \mathrm{~s}$ Absorption of Graphite. Phys. Rev. Lett. 1995, 74 (4), 614-617.

(72) Ma, Y.; Skytt, P.; Wassdahl, N.; Glans, P.; Guo, J.; Nordgren, J. Core Excitons and Vibronic Coupling in Diamond and Graphite. Phys. Rev. Lett. 1993, 71 (22), 3725-3728.

(73) Watts, B.; Ade, H. A Simple Method for Determining Linear Polarization and Energy Calibration of Focused Soft X-Ray Beams. J. Electron Spectrosc. Relat. Phenom. 2008, 162 (2), 49-55. 